Research

\title{
Self-assessed bowel toxicity after external beam radiotherapy for prostate cancer - predictive factors on irritative symptoms, incontinence and rectal bleeding

\author{
Michael Pinkawa*, Marc D Piroth, Karin Fischedick, Sandra Nussen, \\ Jens Klotz, Richard Holy and Michael J Eble
}

Address: Department of Radiation Oncology, RWTH Aachen University, Pauwelsstrasse 30, 52072 Aachen, Germany

Email: Michael Pinkawa* - mpinkawa@ukaachen.de; Marc D Piroth - mpiroth@ukaachen.de; Karin Fischedick - kfischedick@ukaachen.de; Sandra Nussen - snussen@ukaachen.de; Jens Klotz - jklotz@ukaachen.de; Richard Holy - rholy@ukaachen.de;

Michael J Eble-meble@ukaachen.de

* Corresponding author

Published: 2I September 2009

Radiation Oncology 2009, 4:36 doi:10.1 186/1748-717X-4-36

This article is available from: http://www.ro-journal.com/content/4/I/36

(c) 2009 Pinkawa et al; licensee BioMed Central Ltd.

This is an Open Access article distributed under the terms of the Creative Commons Attribution License (http://creativecommons.org/licenses/by/2.0), which permits unrestricted use, distribution, and reproduction in any medium, provided the original work is properly cited.

\begin{abstract}
Background: The aim of the study was to evaluate self-assessed bowel toxicity after radiotherapy (RT) for prostate cancer. In contrast to rectal bleeding, information concerning irritative symptoms (rectal urgency, pain) and incontinence after RT has not been adequately documented and reported in the past.
\end{abstract}

Methods: Patients $(n=286)$ have been surveyed prospectively before $(A)$, at the last day $(70.2-$ 72.0 Gy; B), a median time of two (C) and 16 months after RT (D) using a validated questionnaire (Expanded Prostate Cancer Index Composite). Bowel domain score changes were analyzed and patient-/dose-volume-related factors tested for a predictive value on three separate factors (subscales): irritative symptoms, incontinence and rectal bleeding.

Results: Irritative symptoms were most strongly affected in the acute phase, but the scores of all subscales remained slightly lower at time $D$ in comparison to baseline scores. Good correlations (correlation indices $>0.4 ; p<0.001$ for all) were found between irritative and incontinence function/bother scores at times B-D, suggesting the presence of an urge incontinence for the majority of patients who reported uncontrolled leakage of stool. Planning target volume (PTV), haemorrhoids and stroke in past history were found to be independent predictive factors for rectal bleeding at time D. Chronic renal failure predisposed for lower irritative scores at time D. Paradoxically, patients with greater rectum volumes inside higher isodose levels presented with higher quality of life scores in the irritative and incontinence subscales.

Conclusion: PTV and specific comorbidities are important predictive factors on adverse bowel quality of life changes after RT for prostate cancer. However, greater rectum volumes inside high isodose levels have not been found to be associated with lower quality of life scores. 


\section{Background}

External beam radiation is a well established curative treatment for prostate cancer. As demonstrated in randomized trials, higher doses may improve local control in a subset of these patients [1-3]. Gastrointestinal toxicity is known to be the dose-limiting toxicity [4]. Numerous reports already exist in the literature [5-16].

The standard for measures of toxicity consists of RTOG/ EORTC or CTC morbidity scoring criteria, physicianbased scoring systems that assign a toxicity grade based on symptoms reported by the patient [17-22]. Usually, a grading is reported without the actual symptoms $[1,3,23$ 25 ]. In most cases, higher grades $\geq$ grade 2 indicate rectal bleeding. In a study by Goldner et al[8], 52 (in a total group of 166) patients were reported with grade 2-3 EORTC/RTOG late rectal side effects - the reason was rectal bleeding for 50 patients (96\%). A recently published factor analysis of the EPIC (Expanded Prostate Cancer Index Composite) questionnaire revealed three separate factors within the bowel domain: bleeding, incontinence and irritative symptoms [26]. The information concerning irritative symptoms (rectal urgency, pain) and incontinence is not adequately documented and reported. A potential underestimation of symptoms results from lack of patient reporting. Quality of life questionnaires are used to compensate these problems. The EPIC was found to be more sensitive to changes in bowel toxicity through a course of radiotherapy and correlate well with RTOG/ EORTC scores [27].

The aim of this study was to evaluate gastrointestinal quality of life changes after external beam radiotherapy for prostate cancer with discrimination of the factors concerning rectal bleeding, bowel incontinence and irritative symptoms. Patient-related and dose-volume-related factors were tested for a predictive value, respectively.

\section{Methods}

This study was based on consecutive patients who were treated due to T1-3N0M0 prostatic carcinoma with threedimensional conformal radiotherapy (3DCRT) in the years 2003-2006. The treatment was based on a treatment planning CT scan in supine position with a slice thickness of $5 \mathrm{~mm}$. Patients were asked to have a full bladder for the planning computed tomography (CT) scan and each radiotherapy fraction. In all scans prostate volume, planning target volume (PTV), bladder and rectum were delineated by identifying the external contours. The rectum volume enclosed the region from the anal canal (including the anal canal) to the rectosigmoid flexure. The integral dose (AUC-area under the curve) was defined as the relation of the area under the dose-volume histogram curve to the total area, multiplied by 100 . Treatment plans were calculated using a four-field box technique with $15 \mathrm{MeV}$ pho- tons and a multileaf collimator. The PTV was required to be enclosed by the $90 \%$ isodose relative to the ICRU reference point [28] with a margin of $1.5 \mathrm{~cm}$ in the anterior/ lateral and $1 \mathrm{~cm}$ in the craniocaudal and dorsal directions to the CTV (prostate with or without seminal vesicles). The total dose to the prostate in the reference point was 70.2-72 Gy at 1.8-2.0 Gy daily fractions.

Patients have been surveyed prospectively before (time A), at the last day (B), two months (median, range 6 weeks- 6 months) after (C) and sixteen months (median, range 12-20 months) after (D) radiotherapy using a validated questionnaire, the Expanded Prostate Cancer Index Composite (EPIC) [29]. Only patients with questionnaire results from both time $A$ and time $D$ have been included in the analysis, resulting in 286 (A), 200 (B), 252 (C) and 286 (D) questionnaires at the respective points in time. Nearly all patients who were addressed to respond before treatment agreed to take part in the evaluation (>98\%). The response rate to the last questionnaire was $91 \%$, so that 28 patients who responded before treatment were excluded from the analysis. Baseline patient characteristics are presented in Table 1.

The bowel domain consists of 14 questions for function and the subjective assessment of the associated bother ("no problem" - "very small problem" - "little problem" "moderate problem" - "big problem"). Questions were classified into irritative, incontinence and bleeding subscales. The multi-item scale scores were transformed lineary to a $0-100$ scale, with higher scores representing better health-related quality of life.

The questionnaire was handed over to the patients personally by one of the physicians at time A, B and C. Number of questionnaires was the lowest at the end of radiotherapy (time $\mathrm{B}$ ) because this point in time was limited to a single day (last radiotherapy fraction) and no second opportunity existed for a missed questionnaire. Patients presented in the department six to ten weeks after the end of treatment. Missed questionnaires in the acute phase (time C) and questionnaires one to two years after radiotherapy (time D) were sent to the patients with a return envelope. If a questionnaire was not returned within 4 weeks, patients were contacted by telephone and urged to complete it.

Statistical analysis was performed using the SPSS 14.0 (SPSS, Chicago, Ill), software. To explore statistical HRQOL score differences between different subgroups, the Mann-Whitney-U-test was used. The Wilcoxon's matched-pairs test was applied to determine longitudinal changes in specific subgroups of patients, the Friedman test to consider multiple comparisons. Contingency table analysis with the chi-square test was performed to com- 
Table I: Baseline patient characteristics

\begin{tabular}{|c|c|}
\hline patient age (years); median (range) & $71(45-84)$ \\
\hline planning target volume $\left(\mathrm{cm}^{3}\right)$; median (range) & $336(|69-63|)$ \\
\hline $\begin{array}{l}\text { PSA (ng/ml); median (range) } \\
\leq 10 \mathrm{ng} / \mathrm{ml} ; \mathrm{n}(\%)\end{array}$ & $\begin{array}{l}8(1.2-150) \\
178(62)\end{array}$ \\
\hline biopsy Gleason score <7; n (\%) & $185(65)$ \\
\hline clinical T-stage $\leq 2 \mathrm{a} ; \mathrm{n}(\%)$ & $237(83)$ \\
\hline low risk (PSA $\leq 10 \mathrm{ng} / \mathrm{ml}$; Gleason score $<7$; clinical T-stage $\leq 2 \mathrm{a}$ ); $\mathrm{n}(\%)$ & $106(37)$ \\
\hline intermediate risk (PSA $10-20 \mathrm{ng} / \mathrm{ml}$ or Gleason score $=7$ or clinical T-stage $2 \mathrm{~b}-\mathrm{c}$ ); $\mathrm{n}(\%)$ & $101(35)$ \\
\hline high risk (two risk factors or PSA>20 ng/ml or Gleason score $>7$ or clinical T-stage $>2 \mathrm{c}$ ); $\mathrm{n}(\%$ ) & $79(28)$ \\
\hline neoadjuvant hormonal therapy; n (\%) & $90(32)$ \\
\hline any documented comorbidity;; $\mathrm{n}(\%)$ & $179(63)$ \\
\hline hypertension; n (\%) & $74(26)$ \\
\hline coronary heart disease; $\mathrm{n}(\%)$ & $76(27)$ \\
\hline diabetes; $\mathrm{n}(\%)$ & $34(12)$ \\
\hline chronic obstructive pulmonary disease; n (\%) & $31(11)$ \\
\hline haemorrhoids; n (\%) & $17(6)$ \\
\hline stroke in past history; $\mathrm{n}(\%)$ & $12(4)$ \\
\hline peripheral arterial disease; $\mathrm{n}(\%)$ & $10(4)$ \\
\hline chronic renal failure; $\mathrm{n}(\%)$ & $8(3)$ \\
\hline
\end{tabular}

pare treatment groups with respect to categorical variables. The Spearman correlation coefficient was used to test the correlation between two variables. In a forward stepwise logistic multivariate analysis, different risk factors were tested for their independence. Tested patient-related variables were the comorbidities (see Table 1) and a neoadjuvant hormonal therapy, dose-volume related variables were the PTV, rectum volume and the dose to the rectum. The dose to the rectum was described by the AUC and an additional significant dose level. Cut-off values were defined as parameters with the lowest p-value for differentiation between quality of life changes (volumes tested in $10 \mathrm{~cm}^{3}$ intervals, relative doses in 5\% intervals). All p-values reported are two-sided, $\mathrm{p}<0.05$ is considered significant.

\section{Results}

Quality of life scores before radiotherapy and at different intervals after radiotherapy - with differentiation of irritative symptoms, incontinence and bleeding - are presented in Table 2. In the acute phase, irritative symptom subdomains were most strongly affected. Mean differences $\geq 10$ points in comparison to baseline levels were also reported in incontinence subdomains. Though mean differences for bleeding remained $<5$ points at all intervals, they decreased statistically significantly. Depending on the symptom, 3-7\% more patients reported their bowel symptoms to be a moderate/great problem in comparison to the portion before radiotherapy. While the largest differences (7\%) concerned rectal urgency and increased frequency of bowel movements, the smallest differences (and the smallest percentage at time D) were found for bloody stools (Table 3). 
Table 2: Mean quality of life scores (quartiles in brackets) and differences in relation to baseline scores

\begin{tabular}{|c|c|c|c|c|c|c|c|}
\hline & time $\mathbf{A}$ & $\begin{array}{l}\text { mean diff. } \\
\text { (A-B) }\end{array}$ & time B & $\begin{array}{l}\text { mean diff. } \\
(A-C)\end{array}$ & time C & $\begin{array}{l}\text { mean diff. } \\
\text { (A-D) }\end{array}$ & time D \\
\hline bowel function score & $\begin{array}{c}92 \\
(89 ; 96 ; 100)\end{array}$ & 15 & $\begin{array}{c}78 \\
(68 ; 82 ; 93)\end{array}$ & 5 & $\begin{array}{c}87 \\
(79 ; 93 ; 96)\end{array}$ & 3 & $\begin{array}{c}89 \\
(86 ; 93 ; 100)\end{array}$ \\
\hline irritative function & $\begin{array}{c}89 \\
(85 ; 95 ; 100)\end{array}$ & 18 & $\begin{array}{c}72 \\
(60 ; 75 ; 90)\end{array}$ & 6 & $\begin{array}{c}85 \\
(75 ; 90 ; 100)\end{array}$ & 3 & $\begin{array}{c}87 \\
(81 ; 92 ; 100)\end{array}$ \\
\hline incontinence function & $\begin{array}{c}97 \\
(100 ; 100 ; 100)\end{array}$ & 10 & $\begin{array}{c}88 \\
(100 ; 100 ; 100)\end{array}$ & 4 & $\begin{array}{c}93 \\
(100 ; 100 ; 100)\end{array}$ & 4 & $\begin{array}{c}93 \\
(100 ; 100 ; 100)\end{array}$ \\
\hline rectal bleeding & $\begin{array}{c}99 \\
(100 ; 100 ; 100)\end{array}$ & 4 & $\begin{array}{c}95 \\
(100 ; 100 ; 100)\end{array}$ & 2 & $\begin{array}{c}97 \\
(100 ; 100 ; 100)\end{array}$ & 3 & $\begin{array}{c}96 \\
(100 ; 100 ; 100)\end{array}$ \\
\hline bowel bother score & $\begin{array}{c}93 \\
(93 ; 100 ; 100)\end{array}$ & 20 & $\begin{array}{c}74 \\
(54 ; 82 ; 96)\end{array}$ & 10 & $\begin{array}{c}83 \\
(71 ; 93 ; 100)\end{array}$ & 7 & $\begin{array}{c}86 \\
(79 ; 96 ; 100)\end{array}$ \\
\hline irritative bother & $\begin{array}{c}92 \\
(88 ; 100 ; 100)\end{array}$ & 23 & $\begin{array}{c}69 \\
(44 ; 75 ; 94)\end{array}$ & 12 & $\begin{array}{c}80 \\
(69 ; 94 ; 100)\end{array}$ & 7 & $\begin{array}{c}84 \\
(75 ; 94 ; 100)\end{array}$ \\
\hline incontinence bother & $\begin{array}{c}97 \\
(100 ; 100 ; 100)\end{array}$ & 13 & $\begin{array}{c}86 \\
(100 ; 100 ; 100)\end{array}$ & 10 & $\begin{array}{c}88 \\
(100 ; 100 ; 100)\end{array}$ & 6 & $\begin{array}{c}91 \\
(100 ; 100 ; 100)\end{array}$ \\
\hline rectal bleeding bother & $\begin{array}{c}99 \\
(100 ; 100 ; 100)\end{array}$ & 4 & $\begin{array}{c}95 \\
(100 ; 100 ; 100)\end{array}$ & 3 & $\begin{array}{c}96 \\
(100 ; 100 ; 100)\end{array}$ & 3 & $\begin{array}{c}95 \\
(100 ; 100 ; 100)\end{array}$ \\
\hline
\end{tabular}

$\mathrm{P}<0.0 \mathrm{I}$ for all comparisons relative to baseline scores at time A (Wilcoxon's matched pairs test for individual comparisons and Friedman test for all comparisons in a line)

Good correlations (Spearman correlation coefficients $>0.4 ; \mathrm{p}<0.001$ for all) were found between irritative and incontinence function/bother scores at times B-D, suggesting the presence of an urge incontinence for the majority of patients who reported to have symptoms of fecal incontinence (patients with vs. without rectal urgency $\geq$ once a day reported uncontrolled leakage of stool $\geq$ once a day in $20 \%$ vs. $1 \%$ at time $\mathrm{D} ; \mathrm{p}<0.001$ ). Correlation indices between irritative and rectal bleeding scores were found to be lower (Spearman correlation coefficients 0.25 and $0.30 ; \mathrm{p}<0.001$ for all).

Dose-volume related and patient-related (comorbidities, neoadjuvant hormonal therapy) factors have a significant impact on quality of life score changes (Table 4). The dose-volume histogram reveals a paradoxic association with quality of life changes. Patients with a larger AUC-R, and specifically larger volumes within higher isodose levels (R70, relative rectum volume enclosed by the $70 \%$ isodose presented in Table 4; comparable results were found for cut-off values at $22 \% / 25 \% / 30 \%$ of the rectal volume within the $90 \% / 80 \% / 60 \%$-isodose) reported smaller quality of life changes - irritative and incontinence subdomains were both found to be affected. However, in contrast to patients with a smaller PTV (mean difference: 0 points), patients with a larger PTV presented with lower rectal bleeding scores more than one year after treatment relative to baseline levels. Patients with a chronic renal failure were found to have significantly lower irritative scores in the chronic phase after RT. Haemorrhoids and stroke in past history were important predictors for rectal bleeding at time $\mathrm{D}$.

Haemorrhoids (and other parameters) have not been found to be predictive for rectal bleeding at time A. However, the factors haemorrhoids and NHT (neoadjuvant hormonal therapy) had an independent impact on greater irritative symptoms before RT in multivariate analysis (Table 5). Haemorrhoids clearly increased the probability to have a big/moderate problem with bowel habits overall. This increased risk remained detectable at all intervals after RT. As already presented in Table 4, actually greater quality of life changes after RT have not been found in the function/bother scores or the irritative function/bother subscores for patients with haemorrhoids.

Without an influence already before RT, the multivariate analysis supports the independent influence of larger volumes within higher isodose levels (paradoxic effect) and chronic renal failure on late irritative symptoms; and a larger PTV, larger volumes within higher isodose levels, haemorrhoids and stroke in past history on rectal bleeding (due to an association of NHT with PTV, the effect of NHT has not been found to be independently predictive). 
Table 3: Specific symptoms and associated bother

\begin{tabular}{|c|c|c|c|c|}
\hline & time $\mathbf{A}(\%)$ & time B (\%) & time C (\%) & time D (\%) \\
\hline rectal urgency $\geq$ once a day & 19 & 45 & $19 *$ & $14 *$ \\
\hline uncontrolled leakage of stool $\geq$ once a day & 3 & 7 & $4^{*}$ & $4^{*}$ \\
\hline loose or liquid stools $\geq$ rarely & 53 & 75 & $58^{*}$ & $60^{*}$ \\
\hline bloody stools $\geq$ rarely & 5 & 17 & 9 & 13 \\
\hline painful bowel movements $\geq$ rarely & 22 & 46 & 36 & 30 \\
\hline >two daily bowel movements & 10 & 31 & 18 & 17 \\
\hline crampy pain in the abdomen or rectum $\geq$ once a day & 1 & 15 & 6 & 5 \\
\hline \multicolumn{5}{|l|}{ moderate/big problem from: } \\
\hline rectal urgency & 6 & 32 & 16 & 13 \\
\hline increased frequency of bowel movements & 4 & 30 & 16 & 11 \\
\hline watery bowel movements & 2 & 19 & 11 & 6 \\
\hline losing control of stools & 1 & 12 & 8 & 5 \\
\hline bloody stools & 0 & 3 & 2 & 3 \\
\hline abdominal/rectal pain & 4 & 18 & 13 & 8 \\
\hline bowel habits overall & 6 & 30 & 17 & 13 \\
\hline
\end{tabular}

$\mathrm{P}<0.0$ I for all comparisons relative to baseline scores at time $\mathrm{A}$

$*$ difference not significant $\left(\chi^{2}\right.$-test) in relation to baseline percentage (time $\left.\mathrm{A}\right)$

The PTV was found to be significantly larger for patients with larger rectum volumes inside specific isodoses (mean 353 vs. $284 \mathrm{~cm}^{3}$ with a $770 \geq 25 \%$ vs. $<25 \%$, p $\left.<0.001\right)$. Not a single patient $(\mathrm{n}=80)$ with a PTV $<300 \mathrm{~cm}^{3}$, without haemorrhoids or stroke in the past history reported to have rectal bleeding at time D. A significant effect of the patient age on bowel incontinence was only detectable at time $\mathrm{C}$.

\section{Discussion}

This study reports in detail bowel quality of life changes after 3DCRT, patient-related and dose-volume-related predisposing factors. In contrast to most other studies [13,11-13,25], patients were treated with a homogeneous dose and the same radiotherapy technique. Different dose levels usually coincide with changing treatment margins and radiotherapy techniques, implying possibly confounding variables. Patients after a radical prostatectomy, with a different anatomic situation, have not been included. Previous surgery can be predisposing for greater toxicity [30]. The factors irritation, incontinence and bleeding defined separate quality of life subscales. Usually reported RTOG/EORTC toxicity grades do not allow this perspective. Rectal urgency or incontinence is not considered in these studies [20].

Significant correlations have been found between acute and late quality of life changes, particularly considering the irritative and incontinence domains. As shown by Heemsbergen et al. [31] recently, consequential late damage (non-healing acute response progressing directly into a late effect) is a significant independent factor in the development of late gastrointestinal toxicity.

Rectal bleeding is usually the mostly feared toxicity and in focus of toxicity studies. It is considered a key dose-limiting end point in prostate radiotherapy [4]. In contrast to most other reports, this study does not evaluate a cumulative incidence of rectal bleeding since the end of treatment. The questionnaire asks about a specific period of four weeks. This study demonstrated that rectal bleeding is a subordinated problem in comparison to other prob- 
Table 4: Impact of patient-related and dose-volume-related factors on quality of life score changes

\begin{tabular}{|c|c|c|c|c|}
\hline & factor & $\begin{array}{c}\text { mean diff. } \\
\text { (A-B) }\end{array}$ & $\begin{array}{c}\text { mean diff. } \\
(A-C)\end{array}$ & $\begin{array}{l}\text { mean diff. } \\
\text { (A-D) }\end{array}$ \\
\hline \multirow[t]{5}{*}{ bowel function score } & $A \cup C-R \geq 50 \%$ & 13 vs. 16 & 3 vs. 8 & I vs. $4 \nmid$ \\
\hline & $R 70 \geq 25 \%$ & 15 vs. 16 & 4 vs. $12^{*}$ & 2 vs. $8^{*}$ \\
\hline & coronary heart disease & 17 vs. 14 & 8 vs. $4 \dagger$ & 3 vs. 3 \\
\hline & stroke in past history & 10 vs. 15 & 3 vs. 5 & 7 vs. $3 \dagger$ \\
\hline & chronic renal failure & 30 vs. 15 & 15 vs. 5 & II vs. $3 \dagger$ \\
\hline \multirow[t]{3}{*}{ irritative function } & $A \cup C-R \geq 50 \%$ & 16 vs. 20 & 4 vs. 8 & I vs. $5 \dagger$ \\
\hline & $R 70 \geq 25 \%$ & 18 vs. 18 & 5 vs. $13 \dagger$ & 2 vs. $9 \dagger$ \\
\hline & chronic renal failure & 41 vs. 18 & 8 vs. 6 & 12 vs. $3 \dagger$ \\
\hline \multirow[t]{2}{*}{ incontinence function } & $A \cup C-R \geq 50 \%$ & II vs. 8 & 0 vs. $8 \dagger$ & 2 vs. 6 \\
\hline & $\mathrm{R} 70 \geq 25 \%$ & 10 vs. 8 & 3 vs. $12 \dagger$ & 3 vs. $9 \dagger$ \\
\hline \multirow[t]{5}{*}{ rectal bleeding } & PTV $\geq 300 \mathrm{~cm}^{3}$ & 4 vs. 4 & 2 vs. 2 & 4 vs. $0 *$ \\
\hline & NHT & 4 vs. 4 & 3 vs. 2 & 0 vs. $4^{*}$ \\
\hline & coronary heart disease & 6 vs. 3 & 5 vs. It & 4 vs. 2 \\
\hline & haemorrhoids & 12 vs. 4 & 7 vs. $2 \dagger$ & 9 vs. $3 \dagger$ \\
\hline & stroke in past history & 0 vs. 4 & 0 vs. 2 & 10 vs. $3 *$ \\
\hline \multirow[t]{3}{*}{ bowel bother score } & $R 70 \geq 25 \%$ & 19 vs. 27 & 8 vs. $22^{*}$ & 5 vs. $15^{*}$ \\
\hline & stroke in past history & 9 vs. $20 \dagger$ & 2 vs. 10 & 8 vs. 7 \\
\hline & chronic renal failure & 37 vs. 19 & 11 vs. 10 & 21 vs. $6^{*}$ \\
\hline \multirow[t]{3}{*}{ irritative bother } & $A \cup C-R \geq 50 \%$ & 10 vs.15† & 8 vs. 11 & 6 vs. 7 \\
\hline & $R 70 \geq 25 \%$ & 22 vs. 31 & 10 vs. $26 *$ & 6 vs. 16 \\
\hline & chronic renal failure & 48 vs. 23 & 15 vs. 12 & 22 vs. $7^{*}$ \\
\hline incontinence bother & $R 70 \geq 25 \%$ & II vs. 21 & 9 vs. 16 & 5 vs. $14 \dagger$ \\
\hline \multirow[t]{2}{*}{ rectal bleeding bother } & PTV $\geq 300 \mathrm{~cm}^{3}$ & 4 vs. 6 & 2 vs. 4 & 5 vs. $0 \dagger$ \\
\hline & coronary heart disease & 7 vs. 3 & 5 vs. $2^{*}$ & 3 vs. 4 \\
\hline
\end{tabular}

only factors with significant impact on quality of life changes shown (actually significant differences marked with $\dagger \mathrm{P}<0.05$ or $* \mathrm{P}<0.0 \mathrm{I}$ )

lems from the patients' perspective. Especially in the acute phase (time B and C), irritative symptoms (urgency, frequency, pain) play the major role.

Incontinence was shown to be strongly associated with irritative symptoms. Nearly without exception, a daily incontinence was only reported with a simultaneously present rectal urgency at time D. Anorectal manometry pressures have not been documented in this patient population. Yeoh et al[32] reported significantly reduced anorectal manometry pressures 4 to 6 weeks after radiotherapy for patients with fecal incontinence. However, patients with incontinence were found to have normal basal and squeeze pressures one year after radiotherapy [33]. In a recently published study concerning anorectal function after radiotherapy for prostate cancer, a progressive deterioration of anorectal motor and sensory function has been shown. Rectal compliance progressively decreased and fecal sensitivity to distension increased after treatment [34].
These results focused on a median period of 16 months after treatment. Chronic effects several years after treatment might have additional effects on quality of life. In contrast to rectal bleeding, the cumulative incidence of fecal incontinence has been shown to increase even after more than five years [35]. The percentage of patients with fecal incontinence has been shown to be higher than the incidence of rectal bleeding requiring laser or transfusion in the Dutch dose-escalation trial in both treatment arms (68 Gy and 78 Gy total doses) [35], confirming the findings of our study.

Significant predisposing factors for both rectal bleeding subscale score changes and the symptom "rectal bleeding" in multivariate analysis were the PTV, haemorrhoids and stroke in the past history. A volume-effect is already very well known $[9,10,36]$. Patients with a stroke in the past history always take anticoagulative drugs - this is the most probable reason for the considerably increased tendency for bleeding. Other agents (clopidrogel/ticlopidine) or a 
Table 5: Impact of patient-related and dose-volume-related factors on symptoms/problems in multivariate analysis

\begin{tabular}{|c|c|c|c|c|c|}
\hline & factor & time A & time B & time C & time D \\
\hline & & $\mathrm{HR}[95 \% \mathrm{CI}]$ & ue/incidence & presence vs. & ce of factor \\
\hline \multirow[t]{3}{*}{ painful bowel movements $\geq$ rarely } & $R 70 \geq 25 \%$ & - & - & - & $\begin{array}{c}0.4[0.2-0.9] \\
p=0.03 \\
27 \% \text { vs. } 45 \%\end{array}$ \\
\hline & haemorrhoids & $\begin{array}{c}4.5[1.6-12] \\
p<0.01 \\
53 \% \text { vs. } 20 \%\end{array}$ & $\begin{array}{c}6.3[1.3-30] \\
p=0.02 \\
77 \% \text { vs. } 43 \%\end{array}$ & $\begin{array}{c}2.7[1.0-7.4] \\
p=0.05 \\
59 \% \text { vs. } 34 \%\end{array}$ & - \\
\hline & chronic renal failure & - & - & - & $\begin{array}{c}7.2[1.4-36] \\
P=0.02 \\
75 \% \text { vs. } 29 \%\end{array}$ \\
\hline \multirow[t]{4}{*}{ bloody stools $\geq$ rarely } & PTV $\geq 300 \mathrm{~cm}^{3}$ & - & - & - & $\begin{array}{c}8.2[2.4-28] \\
P<0.0 \mid \\
\mid 7 \% \text { vs. } 4 \%\end{array}$ \\
\hline & $R 70 \geq 25 \%$ & - & - & - & $\begin{array}{c}0.2[0.1-0.6] \\
p<0.01 \\
11 \% \text { vs. } 23 \%\end{array}$ \\
\hline & haemorrhoids & - & - & $\begin{array}{c}3.5[1.0-12] \\
P<0.05 \\
24 \% \text { vs. } 8 \%\end{array}$ & $\begin{array}{c}4.0[1.2-13] \\
p=0.02 \\
29 \% \text { vs. } 12 \%\end{array}$ \\
\hline & stroke in past history & - & - & - & $\begin{array}{c}7.2[2.0-26] \\
p<0.01 \\
42 \% \text { vs. } 12 \%\end{array}$ \\
\hline \multicolumn{6}{|l|}{ moderate/big problem from: } \\
\hline \multirow[t]{3}{*}{ bowel habits overall } & $R 70 \geq 25 \%$ & - & $\begin{array}{c}0.4[0.2-0.9] \\
p=0.03 \\
26 \% \text { vs. } 52 \%\end{array}$ & $\begin{array}{c}0.4[0.2-1.0] \\
p<0.05 \\
15 \% \text { vs. } 32 \%\end{array}$ & - \\
\hline & haemorrhoids & $\begin{array}{c}8.1[2.5-26] \\
p<0.01 \\
29 \% \text { vs. } 5 \%\end{array}$ & $\begin{array}{c}3.4[1.0-1 I] \\
p<0.05 \\
62 \% \text { vs. } 28 \%\end{array}$ & $\begin{array}{c}5.9[2.1-17] \\
p<0.01 \\
53 \% \text { vs. } 15 \%\end{array}$ & $\begin{array}{c}3.3[1.1-10] \\
p=0.04 \\
29 \% \text { vs. } 12 \%\end{array}$ \\
\hline & chronic renal failure & - & - & - & $\begin{array}{c}7.9[1.9-33] \\
p<0.01 \\
50 \% \text { vs. } 12 \%\end{array}$ \\
\hline \multirow[t]{4}{*}{ rectal urgency } & $R 70 \geq 25 \%$ & - & - & $\begin{array}{c}0.3[0.1-0.6] \\
p<0.01 \\
13 \% \text { vs. } 35 \%\end{array}$ & - \\
\hline & $\mathrm{NHT}$ & $\begin{array}{c}4.3[1.5-12] \\
P<0.01 \\
\mid 1 \% \text { vs. } 3 \%\end{array}$ & - & - & - \\
\hline & haemorrhoids & $\begin{array}{c}5.2[1.5-12] \\
p=0.03 \\
18 \% \text { vs. } 5 \%\end{array}$ & $\begin{array}{c}3.7[1.2-12] \\
p=0.03 \\
62 \% \text { vs. } 30 \%\end{array}$ & - & $\begin{array}{c}3.4[1.1-10] \\
p=0.03 \\
29 \% \text { vs. } 12 \%\end{array}$ \\
\hline & chronic renal failure & - & - & - & $\begin{array}{c}4.9[1.1-22] \\
p=0.04 \\
28 \% \text { vs. } 12 \%\end{array}$ \\
\hline losing control of stools & age $\geq 70$ years & - & - & $\begin{array}{c}3.6[1.0-12] \\
P<0.05 \\
I I \% \text { vs. } 3 \%\end{array}$ & - \\
\hline bloody stools & haemorrhoids & - & - & - & $\begin{array}{c}7.0[1.2-39] \\
p=0.03 \\
12 \% \text { vs. } 2 \%\end{array}$ \\
\hline
\end{tabular}


higher aspirin dose is used in comparison with patients with coronary artery disease of peripheral artery disease. The association of anticoagulants with acute and late rectal bleeding has been shown in other studies before $[37,38]$.

Haemorrhoids have been reported to be predictive for acute tenesmus and rectal bleeding after 3DCRT before [39]. Our study very well demonstrates the predisposition for irritative symptoms already before 3DCRT, so that quality of life changes did not differ significantly. However, the effect on rectal bleeding became only evident after 3DCRT.

Higher volumes within higher isodose levels were associated with smaller quality of life changes in the irritative and incontinence subscales after 3DCRT. The multivariate analysis demonstrates the independence concerning irritative symptoms. This result may be associated with the specific dose constellation and treatment technique in our patient group. Yeoh et al[34] reported a significantly lower incidence of rectal urgency for patients after 2DCRT vs. 3DCRT in spite of a considerably larger PTV - these patients have likewise been treated with a four-field technique and doses not exceeding $72 \mathrm{~Gy}$.

The reduction of irritative symptoms (urgency, frequency, pain) can be the consequence of a radiation effect on peripheral nerves. In the case of all nervous tissues, a dose of $60 \mathrm{~Gy}$ is associated with a less than $5 \%$ probability of injury, but this rises steeply with increased radiation dose. The pathogenesis involves progressive vascular degeneration, fibrosis and demyelination with loss of nerve fibres. The latency period ranges from 6 months to several years [40]. Comparably to an earlier development of erectile dysfunction [41], also usually considered as a chronic effect, differences have already been detected a few weeks after 3DCRT. Higher total doses, exceeding 72 Gy, can be expected to be associated with an increased risk of rectal ulcerations [35].

The association of larger rectum volumes within specific isodose levels with a paradoxically improved quality of life in the bowel domain was already found in a preliminary analysis of the first eighty patients [14]. This association was also found in an independent group of patients after permanent brachytherapy with I-125 as monotherapy for prostate cancer [42]. Quality of life scores have not been correlated with dose-volume histogram parameters for the rectum in the literature before. However, a validation of this association by other centres is needed.

Chronic renal failure is a rare comorbidity in a population of prostate cancer patients, with only $3 \%$ affected in our patient population. It has not been considered as a predis- posing factor for toxicity before. This study has shown a dramatically increase risk of toxicity (specifically irritative symptoms), proven to be highly significant only more than one year after radiotherapy in spite of a low disease incidence. Metabolic effects must be postulated as the reason for this finding, but the actual mechanism is not clear (possibly slightly higher blood levels of toxic agents). This finding has to be taken into account in the treatment decision process for these patients.

\section{Conclusion}

Irritative symptoms constitute the major problem for patients in the acute phase during and after external beam radiotherapy for prostate cancer. Irritative symptoms, incontinence and rectal bleeding are all affected in the chronic phase. Rectal bleeding - usually estimated to be the most worrying symptom - is bothering the patients less in comparison to irritative symptoms and incontinence. Depending on the symptom, 3-7\% more patients reported their bowel symptoms to be a moderate/great problem in relation to baseline values before radiotherapy. Incontinence correlates significantly with irritative symptoms.

Planning target volume, haemorrhoids and stroke in past history were found to be independent predictive factors for chronic rectal bleeding. However, greater rectum volumes inside high isodose levels have not been found to be associated with lower quality of life scores.

\section{Competing interests}

The authors declare that they have no competing interests.

\section{Authors' contributions}

MP, MJE have made substantial contributions to conception and design; MP and KF have made substantial contributions to acquisition of data; MP, MDP, KF, SN, JK, RH, MJE to analysis and interpretation of data. MP has been involved in drafting the manuscript. MDP, KF, SN, JK, RH, MJE revised it critically for important intellectual content. All authors have given final approval of the version to be published.

\section{Acknowledgements}

The study was funded by the research resources of the Department of Radiation Oncology, RWTH Aachen University, Germany. We would like to thank the staff who took care of our patients' needs, and who were involved in gathering, documenting, verifying, forwarding, and processing the clinical data.

\section{References}

I. Kuban DA, Tucker SL, Dong L, Starkschall G, Huang EH, Cheung MR, Lee AK, Pollack A: Long-term results of the M.D. Anderson randomized dose-escalation trial for prostate cancer. Int J Radiat Oncol Biol Phys 2008, 70:67-74.

2. Peeters ST, Heemsbergen WD, Koper PC, van Putten WL, Slot A, Dielwart MF, Bonfrer JM, Incrocci L, Lebesque JV: Dose-response in radiotherapy for localized prostate cancer: results of the 
Dutch multicenter randomized phase III trial comparing 68 Gy of radiotherapy with 78 Gy. J Clin Oncol 2006, 24:1990-1996.

3. Zietman AL, DeSilvio M, Slater JD, Rossi CJ, Miller DW, Adams JA Shipley WU: Comparison of conventional-dose vs. high-dose radiation therapy in clinically localized adenocarcinoma of the prostate. JAMA 2005, 294:1233-1239.

4. Brenner DJ: Fractionation and late rectal toxicity. Int J Radiat Oncol Biol Phys 2004, 60:1013-1015.

5. Akimoto T, Muramatsu H, Takahashi M, Saito J, Kitamoto Y, Harashima K, Miyazawa Y, Yamada M, Ito K, Kurokawa K, et al.: Rectal bleeding after hypofractionated radiotherapy for prostate cancer: correlation between clinical and dosimetric parameters and the incidence of grade 2 or worse rectal bleeding. Int J Radiat Oncol Biol Phys 2004, 60:1033-1039.

6. Goldner G, Wachter-Gerstner N, Wachter S, Dieckmann K, Janda M, Potter R: Acute side effects during 3-D-planned conformal radiotherapy of prostate cancer. Differences between patient's self-reported questionnaire and the corresponding doctor's report. Strahlenther Onkol 2003, 179:320-327.

7. Goldner G, Zimmermann F, Feldmann H, Glocker S, Wachter-Gerstner N, Geinitz H, Becker G, Potzi R, Wambersie A, Bamberg M, et al.: 3-D conformal radiotherapy of localized prostate cancer: a subgroup analysis of rectoscopic findings prior to radiotherapy and acute/late rectal side effects. Radiother Oncol 2006 78:36-40.

8. Goldner G, Tomicek B, Becker G, Geinitz H, Wachter S, Zimmermann F, Wachter-Gerstner N, Reibenwein J, Glocker S, Bamberg M, et al.: Proctitis after external-beam radiotherapy for prostate cancer classified by Vienna Rectoscopy Score and correlated with EORTC/RTOG score for late rectal toxicity: results of a prospective multicenter study of 166 patients. Int J Radiat Oncol Biol Phys 2007, 67:78-83.

9. Jackson A, Skwarchuk MW, Zelefsky MJ, Cowen DM, Venkatraman ES, Levegrun S, Burman CM, Kutcher G], Fuks Z, Liebel SA, et al: Late rectal bleeding after conformal radiotherapy of prostate cancer. II. Volume effects and dose-volume histograms. Int J Radiat Oncol Biol Phys 200I, 49:685-698.

10. Karlsdottir A, Johannessen DC, Muren LP, Wentzel-Larsen T, Dahl $O$ : Acute morbidity related to treatment volume during 3Dconformal radiation therapy for prostate cancer. Radiother Oncol 2004, $71: 43-53$.

1I. Michalski JM, Winter K, Purdy JA, Wilder RB, Perez CA, Roach M, Parliament MB, Pollack A, Markoe AM, Harms W, et al.: Preliminary evaluation of low-grade toxicity with conformal radiation therapy for prostate cancer on RTOG 9406 dose levels I and II. Int J Radiat Oncol Biol Phys 2003, 56:192-198.

12. Michalski JM, Winter K, Purdy JA, Perez CA, Ryu JK, Parliament MB, Valicenti RK, Roach M III, Sandler HM, Markoe AM, et al.: Toxicity after three-dimensional radiotherapy for prostate cancer with RTOG 9406 dose level IV. Int J Radiat Oncol Biol Phys 2004, 58:735-742.

13. Michalski JM, Winter K, Purdy JA, Parliament M, Wong H, Perez CA, Roach M, Bosch W, Cox JD: Toxicity after three-dimensional radiotherapy for prostate cancer on RTOG 9406 dose Level V. Int J Radiat Oncol Biol Phys 2005, 62:706-7/3

14. Pinkawa M, Fischedick K, Asadpour B, Gagel B, Piroth MD, Eble MJ: Low-grade toxicity after conformal radiation therapy for prostate cancer--impact of bladder volume. Int J Radiat Oncol Biol Phys 2006, 64:835-84I.

15. Skwarchuk MW, Jackson A, Zelefsky MJ, Venkatraman ES, Cowen DM, Levegrun S, Burman CM, Fuks Z, Leibel SA, Ling CC: Late rectal toxicity after conformal radiotherapy of prostate cancer (I): multivariate analysis and dose-response. Int J Radiat Oncol Biol Phys 2000, 47:103-II3.

16. Zapatero A, Garcia-Vicente F, Modolell I, Alcantara P, Floriano A, Cruz-Conde A, Torres JJ, Perez-Torrubia A: Impact of mean rectal dose on late rectal bleeding after conformal radiotherapy for prostate cancer: dose-volume effect. Int J Radiat Oncol Biol Phys 2004, 59:1343-1351.

17. Cox JD, Stetz JA, Pajak TF: Toxicity criteria of the radiation therapy oncology group (RTOG) and the european organization for research and treatment of cancer (EORTC). Int J Radiat Oncol Biol Phys 1995, 3 I: I34 I-1346.

18. Pavy JJ, Denekamp J, Letschert J, Littbrand B, Mornex F, Bernier J, Gonzales-Gonzales D, Horiot J, Bolla M, Bartelink H: EORTC late effects working group. Late effects toxicity scoring: the SOMA scale. Radiother Oncol 1995, 35: II-15.

19. Trotti A, Colevas AD, Setser A, Rusch V, Jaques D, Budach V, Murphy B, Cumberlin R, Coleman CN, Rubin P: CTCAE v3.0:development of a comprehensive grading system for the adverse effects of cancer treatment. Semin Radiat Oncol 2003, 13:|76-|8|.

20. Laan HP van der, Bergh A van den, Schilstra C, Vlasman R, Meertens $\mathrm{H}$, Langendijk JA: Grading-system-dependent volume effects for late radiation-induced rectal toxicity after curative radiotherapy for prostate cancer. Int J Radiat Oncol Biol Phys 2008, 70: I I38-I I 45.

21. Lips IM, Dehnad H, van Gils CH, Boeken Kruger AE, Heide UA van der, van Vulpen M: High-dose intensity-modulated radiotherapy for prostate cancer using daily fiducial marker-based position verification: acute and late toxicity in 331 patients. Radiat Oncol 2008, 3:15.

22. Ghadjar P, Vock J, Vetterli D, Manser P, Bigler R, Tille J, Madlung A Behrensmeier F, Mini R, Aebersold DM, et al:: Acute and late toxicity in prostate cancer patients treated by dose escalated intensity modulated radiation therapy and organ tracking. Radiat Oncol 2008, 3:35

23. Arcangeli S, Saracino B, Petrongari MG, Gomellini, Marzi S, Landoni V, Gallucci M, Sperduti I, Arcangeli G: Analysis of toxicity in patients with high risk prostate cancer treated with intensity-modulated pelvic radiation therapy and simultaneous integrated dose escalation to prostate area. Radiother Oncol 2007, 84: I 48-I55.

24. Karlsdottir A, Muren LP, Wentzel-Larsen T, Dahl O, Karlsdottir A Muren LP, Wentzel-Larsen T, Dahl O: Late gastrointestinal morbidity after three-dimensional conformal radiation therapy for prostate cancer fades with time in contrast to genitourinary morbidity. Int J Radiat Oncol Biol Phys 2008, 70:। $478-1486$.

25. Zelefsky MJ, Levin EJ, Hunt M, Yamada Y, Shippy AM, Jackson A, Amols $\mathrm{HI}$ : Incidence of late rectal and urinary toxicities after three-dimensional conformal radiotherapy and intensitymodulated radiotherapy for localized prostate cancer. Int J Radiat Oncol Biol Phys 2008, 70: I 124-I I 29

26. Volz-Sidiropoulou E, Pinkawa M, Fischedick K, Jakse G, Gauggel S, Eble MI: Factor analysis of the Expanded Prostate Cancer Index Composite (EPIC) in a patient group after primary (external beam radiotherapy and permanent iodine-125 brachytherapy) and postoperative radiotherapy for prostate cancer. Curr Urol 2008, 2:129.

27. Muanza TM, Albert PS, Smith S, Godette D, Crouse NS, Cooley-Zgela T, Sciuto L, Camphausen K, Coleman CN, Menard C, et al.: Comparing measures of acute bowel toxicity in patients with prostate cancer treated with external beam radiation therapy. Int J Radiat Oncol Biol Phys 2005, 62:1316-1321.

28. International Commission on Radiation Units and Measurements (ICRU): ICRU Report 50: Prescribing, recording and reporting photon beam therapy. Bethesda, MD: ICRU; 1993.

29. Wei JT, Dunn RL, Litwin MS, Sandler HM, Sanda MG, Wei JT, Dunn RL, Litwin MS, Sandler HM, Sanda MG: Development and validation of the expanded prostate cancer index composite (EPIC) for comprehensive assessment of health-related quality of life in men with prostate cancer. Urology 2000, 56:899-905.

30. Fiorino C, Fellin G, Rancati T, Vavassori V, Bianchi C, Borca VC Girelli G, Mapelli M, Menegotti L, Nava S, et al.: Clinical and dosimetric predictors of late rectal syndrome after 3D-CRT for localized prostate cancer: preliminary results of a multicenter prospective study. Int J Radiat Oncol Biol Phys 2008, 70:1130-1137.

3I. Heemsbergen WD, Peeters STH, Koper PCM, Hoogeman MS, Lebesque JV: Acute and late gastrointestinal toxicity after radiotherapy in prostate cancer patients. Int J Radiat Oncol Biol Phys 2006, 66:3-10.

32. Yeoh EK, Russo A, Botten R, Fraser R, Roos D, Penniment M, Borg $M$, Sun WM: Acute effects of therapeutic irradiation for prostatic carcinoma on anorectal function. Gut 1998, 43:123-127.

33. Yeoh EK, Botten R, Russo A, MCGowan R, Fraser R, Roos D, Penniment M, Borg M, Sun W: Chronic effects of therapeutic irradiation for localized prostatic carcinoma on anorectal function. Int J Radiat Oncol Biol Phys 2000, 47:915-924. 
34. Yeoh EK, Holloway RH, Fraser RJ, Botten R, Di Matteo A, Moore JW, Schoeman MN, Bartholomeusz DL: Anorectal function after three- versus two-dimensional radiation therapy for carcinoma of the prostata. Int J Radiat Oncol Biol Phys 2009, 73:46-52.

35. Al-Mamgani A, van Putten WL, Heemsbergen WD, van Leenders GJLH, Slot A, Dielwart MFH, Incrocci L, Lebesque JV: Update of dutch multicenter dose-escalation trial of radiotherapy for localized prostate cancer. Int J Radiat Oncol Biol Phys 2008, 72:980-988.

36. Kuban D, Pollack A, Huang E, Levy L, Dong L, Starkschall G, Rosen I: Hazards of dose escalation in prostate cancer radiotherapy. Int J Radiat Oncol Biol Phys 2003, 57:1260-1268.

37. Choe KS, Jani AB, Liauw SL: Should radiation therapy be modified for prostate cancer patients on anticoagulants? Int J Radiat Oncol Biol Phys 2007, 69:S3I3-S3I4.

38. Takeda K, Ogawa Y, Ariga H, Koto M, Sakayauchi T, Fujimoto K, Narazaki K, Mitsuya M, Takai Y, Yamada S: Clinical correlations between treatment with anticoagulants/antiaggregants and late rectal toxicity after radiotherapy for prostate cancer. Anticancer Research 2009, 29:1831-1834.

39. Vavassori V, Fiorino C, Rancati T, Magli A, Fellin G, Baccolini M, Bianchi C, Cagna E, Mauro FA, Monti AF, et al:: Predictors for rectal and intestinal acute toxicities during prostate cancer high-dose 3D-CRT: results of a prospective multicenter study. Int J Radiat Oncol Biol Phys 2007, 67: | 401-1410.

40. Kogel AJ van der: Radiation response and tolerance of normal tissues. Basic clinical radiobiology. London 2002:30-4I.

41. Pinkawa M, Gagel B, Piroth MD, Fischedick K, Asadpur B, Kehl M, Klotz J, Eble MJ: Erectile dysfunction after external beam radiotherapy for prostate cancer. Eur Urol 2008, 55:227-236.

42. Pinkawa M, Piroth MD, Holy R, Klotz J, Nussen S, Borchers H, Heidnreich A, Eble MJ: Rectal morbidity following permanent interstitial brachytherapy for prostate cancer - impact of day I vs. day 30 computed tomography post-implant dosimetry. Brachytherapy in press.

Publish with Bio Med Central and every scientist can read your work free of charge

"BioMed Central will be the most significant development for disseminating the results of biomedical research in our lifetime. "

Sir Paul Nurse, Cancer Research UK

Your research papers will be:

- available free of charge to the entire biomedical community

- peer reviewed and published immediately upon acceptance

- cited in PubMed and archived on PubMed Central

- yours - you keep the copyright
BioMedcentral 